\title{
EDUCAÇÃO AMBIENTAL E DESENVOLVIMENTO SUSTENTÁVEL NA FORMAÇÃO EM CIÊNCIAS CONTÁBEIS
}

\author{
Alison Ítalo de Souza Melo ${ }^{1}$ \\ Josicleide de Amorim Pereira Moreira ${ }^{2}$ \\ Esdras dos Santos Carvalho ${ }^{3}$ \\ Maria das Graças Gonçalves Vieira Guerra ${ }^{4}$ \\ Raimundo Aprígio Menezes Júnior ${ }^{5}$
}

Resumo: Este trabalho verificou se o curso de Ciências Contábeis de uma universidade federal do sertão alagoano propicia a Educação Ambiental com vistas ao desenvolvimento sustentável. Para tanto, adotou-se a pesquisa descritiva, com método quantitativo para a abordagem do problema, tendo sido aplicado um questionário junto aos formandos para a coleta de dados. Os resultados obtidos apontam que o curso pesquisado não propicia a Educação Ambiental de forma transversal e que, em sua maior parte, os discentes que tiveram acesso às temáticas sobre questões ambientais e do desenvolvimento sustentável foram aqueles que cursaram a disciplina Contabilidade Ambiental, intuindo-se que ela contempla a temática socioambiental.

Palavras-chave: Educação Ambiental; Contabilidade Ambiental; Ciências Contábeis.

Abstract: This work verified if the Accounting Sciences course at a federal university, in the backlands of Alagoas, provides Environmental Education aiming to sustainable development. Therefore, descriptive research was adopted with a quantitative method to approach the problem, and a questionnaire was applied to the trainees for data collection. The obtained results point out that the researched course does not provide Environmental Education in a cross-sectional way and that, for the most part, the students who had access to the themes on environmental issues and sustainable development were those who attended the Environmental Accounting discipline, once it encompasses the socio-environmental theme.

Keywords: Environmental Education; Environmental Accounting; Accounting Sciences.

\footnotetext{
1 Universidade Federal de Alagoas. E-mail: alisonitalosouzamelo@gmail.com

2 Universidade Federal de Alagoas. E-mail: josicleideamorim@gmail.com.

3 Universidade Federal de Alagoas. E-mail: esdras.carvalho@santana.ufal.br.

${ }^{4}$ Universidade Federal da Paraíba. E-mail: gracinhavieira@yahoo.com.br.

5 Universidade Federal da Paraíba. E-mail: jrmenezes@cear.ufpb.br.
} 


\section{Introdução}

As questões ambientais estão cada vez mais presentes nas pautas das discussões do desenvolvimento sustentável. Isso se dá pelo fato de ser perceptível a necessidade de mudanças relacionadas à produção e ao consumo, tendo em vista as externalidades provocadas ao meio ambiente.

O meio ambiente tem ligação direta com a sobrevivência da espécie humana e todos os demais seres. Sua definição foi proferida na Conferência das Nações Unidas sobre o Meio Ambiente, em 1972, como "conjunto de componentes físicos, químicos, biológicos e sociais capazes de causar efeitos diretos ou indiretos, em um prazo curto ou longo, sobre os seres vivos e as atividades humanas".

A Conferência objetivou conscientizar a sociedade em termos de melhoria da relação do homem com o meio ambiente, de modo a atender as necessidades atuais da população, mais também, visando à sobrevivência das gerações futuras.

Urge conservar o meio ambiente como garantia da sobrevivência da humanidade e dos ecossistemas de nosso planeta. Contudo, o que se presencia ao longo dos anos é a degradação ambiental em decorrência da ação humana, seja por explorar atividades com ações excessivas sobre os recursos naturais ou por seus efeitos potencialmente poluidores.

Em vista disso, vários movimentos ambientalistas têm surgido no sentido de discutir a conservação, bem como a preservação do meio ambiente associado a soluções que ensejem o desenvolvimento sustentável.

A Comissão Mundial sobre Meio Ambiente e Desenvolvimento, por meio do relatório Brundtland, definiu desenvolvimento sustentável como aquele capaz de atender "as necessidades do presente sem comprometer a capacidade das gerações futuras para atender as suas necessidades" (CMMAD, 1991, p. 46). O referido relatório foi um dos pioneiros a apresentar diretrizes que buscam solucionar as questões socioambientais em uma escala global.

Por essas vias, várias ações têm sido envidadas por organizações nacionais e internacionais, pelo governo e pela sociedade civil no sentido de mitigar os efeitos degradantes que impactam o meio ambiente.

Assim, em resposta a crescente preocupação da sociedade em relação à conservação e à preservação do meio ambiente, nas últimas décadas foram editadas leis e políticas que asseguram o cumprimento dos dispositivos legais direcionados à minimização dos impactos ambientais.

Concomitantemente a isso, as empresas, por sua vez, têm buscado realizar suas atividades em combinação com ações socioambientais, objetivando, entre outros interesses, sua perenidade no mercado. Para tanto, divulgam suas ações, de modo a legitimar a imagem corporativa, já que essa veiculação tem como um dos seus objetivos minimizar as pressões da 
sociedade e evidenciar suas responsabilidades como prioridade na relação com o ambiente na qual estão inseridas (SAMPAIO, 2011).

Entretanto, não é difícil perceber o fosso existente entre as ações que buscam minimizar os efeitos degradantes resultantes das atividades empresariais e a busca constante pelo desenvolvimento econômico, evidenciando que falta muito a ser feito no sentido de equalizar a condição de desenvolvimento sustentável.

Saliente-se que as mudanças ambientais não dependem somente das empresas envolvidas, cabe à conscientização da sociedade acerca dos problemas existentes e dos que poderão surgir, uma vez que através da conscientização desses problemas seria possível reivindicar práticas de sustentabilidade junto às empresas, bem como ao legislador que elabora as leis e políticas públicas (ESCRIVÃO; NAGAMO, 2014).

Nesse sentido, sensibilizar a população quanto ao seu papel em relação às práticas ambientais é uma questão sine qua non para uma relação equilibrada entre o meio ambiente e o desenvolvimento sustentável.

Para tanto, coloca-se a educação como a base para a conscientização e sensibilização da população no que tange ao processo de mudanças de práticas que degradam o meio ambiente.

Nesse diapasão, a Educação Ambiental (EA) surge como um horizonte para refletir sobre a complexidade dos problemas ambientais. Na opinião de Leff (2001) a formação ambiental é necessária para se compreender a transformação da realidade provocada pela problemática do desenvolvimento, a qual implica um processo mais orgânico e reflexivo de reorganização do saber, bem como da sociedade na elaboração de novas capacidades compreensivas e intervencionistas na transformação do mundo.

Um dos processos que marcaram o início da discussão sobre Educação Ambiental foi a Conferência Intergovernamental de Tbilisi, na Antiga União Soviética, sendo considerado um dos principais eventos sobre Educação Ambiental do planeta. Essa conferência foi organizada a partir de uma parceria entre a UNESCO e o Programa de Meio Ambiente da ONU - PNUMA e, desse encontro, saíram as definições, os objetivos, os princípios e as estratégias para a Educação Ambiental no mundo. Dentre os seus objetivos está o de que o processo educativo deveria ser orientado para a resolução dos problemas concretos do meio ambiente, através de enfoques interdisciplinares, e de participação ativa e responsável de cada indivíduo e da coletividade (PORTAL DA EDUCAÇÃO, 2013).

No Brasil, a conferência de Tbilisi influenciou a adoção e criação de alguns benefícios para o país referentes às normas ambientais, como a criação da Lei n 6.938/81, especificamente em seu artigo 2 que dispõe sobre a Política Nacional do Meio Ambiente, assim como elenca os princípios a serem seguidos sobre a preservação do meio ambiente. Nesse seguimento, em seu inciso X, o referido artigo ainda preceitua a "Educação Ambiental a todos os níveis de 
ensino, inclusive a educação da comunidade, objetivando capacitá-la para a participação ativa na defesa do meio ambiente".

Sobre este ponto, Morales (2007) destaca que as universidades como matriz formadora tem um papel fundamental junto à sociedade podendo criar $\mathrm{e}$ desenvolver políticas socioambientais dentro e fora do seu campo de atuação, de modo a produzir e guiar um conjunto de transformações.

Com efeito, a universidade é considerada como o templo do saber e tem um papel importante na formação dos profissionais das mais variadas áreas. Logo, introduzir em seu seio valores e conceitos ambientais que possibilitem uma reflexão crítica e participativa dos discentes em relação às questões ambientais promoverá uma formação transformadora, já que a partir disso se vislumbra que os formandos, conscientes de sua importância nesse processo, possam, em sua atuação profissional, interferir de maneira positiva na melhoria da qualidade do meio ambiente.

Dada a importância da temática, o objetivo dessa pesquisa é verificar se o curso de Ciências Contábeis de uma universidade federal do sertão alagoano propicia a Educação Ambiental com vistas ao desenvolvimento sustentável.

Destaca-se que estudos dessa natureza são importantes para evidenciar que a Educação Ambiental se faz necessária na formação em qualquer área de saber, uma vez que se objetiva a possibilidade de conscientizar os futuros profissionais acerca da necessidade de conservar e preservar o meio ambiente.

Por essas vias, justifica-se a realização dessa pesquisa na formação em Ciências Contábeis, uma vez que os futuros profissionais da área terão que lidar com situações que perpassam por questões ambientais, como é o caso da Contabilidade Ambiental, fazendo-se necessário o contato com conceitos e valores durante o período formativo, já que o contador auxiliará na tomada de decisão dos gestores, as quais, de alguma forma, poderão trazer algum reflexo impactante ao meio ambiente, necessitando, portanto, de novos estudos acerca da temática.

Vários estudos foram realizados, a exemplo de Ribeiro (2018), que buscou analisar o nível de conhecimento dos estudantes e profissionais da cidade de Santana do Ipanema - AL acerca da Contabilidade Ambiental. Também, Pereira (2014) analisou, no contexto da Contabilidade Ambiental, os conhecimentos dos futuros contadores de uma instituição pública de ensino superior do estado da Paraíba. Além do realizado por Maciel et al. (2009) que objetivou analisar o conhecimento dos profissionais de contabilidade de Pernambuco, no que tange a Contabilidade Ambiental. Contudo, percebe-se a carência de pesquisas que verifiquem a abordagem de conhecimentos acerca de questões ambientais e do desenvolvimento sustentável, as quais podem utilizar como escopo a Contabilidade Ambiental, evidenciando-se, com isso, a necessidade de novas reflexões quanto à formação em Ciências Contábeis. 
A pesquisa torna-se relevante por contribuir com estudos futuros a serem realizados pelos acadêmicos, bem como por possibilitar aos profissionais conhecerem a importância da temática para área, vislumbrandose contadores preparados para o enfrentamento das questões ambientais que permeiam toda a sociedade.

\section{Procedimentos Metodológicos}

Para a realização deste trabalho se optou, quanto aos seus objetivos, pela pesquisa descritiva, uma vez que tal tipologia relata fenômenos reais, bem como situações e eventos, de modo a identificar problemas e justificar condições, além de permitir comparar situações e problemas semelhantes (GRESSLER, 2004). Neste sentido, esse tipo de pesquisa auxiliou na verificação se o curso de Ciências Contábeis, da universidade pesquisada, contempla conhecimentos acerca de questões ambientais e do desenvolvimento sustentável, ensejando à Educação Ambiental.

Quanto aos procedimentos técnicos, adotou-se a pesquisa bibliográfica e a de levantamento. A bibliográfica compreendeu a revisão de literatura por meio de consultas a periódicos científicos, anais de congressos, livros, revistas, dentre outras publicações que tratam da temática estudada (MARCONI; LAKATOS, 2007). Enquanto a de levantamento se caracteriza pela interrogação direta das pessoas cujo comportamento se deseja conhecer (GIL, 2002). Por essas vias, a pesquisa de levantamento foi adotada, tendo em vista a pretensão de interrogar os discentes de um curso de Ciências Contábeis para o alcance do objetivo deste estudo.

No que tange à abordagem do problema, empregou-se o método quantitativo, caracterizado pelo emprego de instrumentos estatísticos, tanto na coleta quanto no tratamento dos dados (BEUREN, 2012). Assim, a abordagem quantitativa foi empregada por conta da utilização de instrumentos estatísticos que contribuíram para a construção das tabelas que evidenciaram as frequências e percentuais de respostas em relação às indagações levantadas.

O universo da pesquisa foi composto por discentes do oitavo período (último período) do curso de Ciências Contábeis de uma universidade federal do sertão alagoano correspondendo a um total de quarenta graduandos.

A amostra da pesquisa, de natureza não probabilística, considerou o critério de acessibilidade, constituindo-se, portanto, por 37 (trinta e sete) estudantes matriculados no oitavo período do curso.

Como instrumento de coleta de dados, foi aplicado, de forma presencial, junto aos discentes participantes da pesquisa, um questionário contendo onze questões fechadas.

Os dados resultantes da aplicação do questionário foram tabulados, organizados e tratados por meio do software Microsoft Office Excel, sendo os resultados apresentados em formatos de tabelas. 
Os resultados obtidos passaram por uma análise descritiva com a aplicação de técnicas simples de estatísticas, sendo os mesmos correlacionados com o embasamento teórico que sustentou a pesquisa.

\section{Educação Ambiental no Brasil}

A Educação Ambiental originou-se dos debates acerca dos problemas ambientais provocados pelo o uso desordenado dos recursos naturais. Tais debates fomentaram a criação de legislações com vistas à defesa do meio ambiente e sua integração com a educação, objetivando inserir na sociedade conhecimentos que promovam mudanças no modo de produção e de consumo, ensejando o desenvolvimento sustentável.

Assim, a Educação Ambiental no contexto brasileiro necessitou, inicialmente, de um ambiente regulatório que envidasse esforços no sentido de garantir a sua inserção no ambiente educacional. A priori, tais esforços tiveram sua materialização com a criação da Secretaria Especial do Meio Ambiente (Sema) no ano de 1973.

O nascedouro da Educação Ambiental, como princípio e instrumento de política ambiental, teve o seu aporte por meio da Lei $n^{\circ} 6.938 / 81$, que dispõe sobre a Política Nacional do Meio Ambiente (PNMA) a qual estabeleceu, em seu artigo $2^{\circ}$, inciso X, a necessidade de promover a "Educação Ambiental a todos os níveis de ensino, inclusive a educação da comunidade, objetivando capacitá-la para participação ativa na defesa do meio ambiente" (BRASIL, 1981).

Em consonância, a Constituição Federal do Brasil de 1988, por meio do seu Art. 225, parágrafo 1, inciso VI, atribuiu ao Estado o dever de "promover a Educação Ambiental em todos os níveis de ensino e a conscientização pública para a preservação do meio ambiente" (BRASIL, 1988). Reconhecendo-se, portanto, a todos os cidadãos brasileiros o direito constitucional à Educação Ambiental. A partir disso, várias outras ações foram desenvolvidas, a exemplo do I Fórum Brasileiro de Educação Ambiental que aconteceu no ano de 1989.

A década de noventa foi marcada pela criação dos Grupos de Trabalho de Educação Ambiental do Ministério de Educação e Cultura (MEC) e do Ministério do Meio Ambiente (MMA). Também foram criados: a Divisão de Educação Ambiental do Instituto Brasileiro de Meio Ambiente e dos Recursos Naturais Renováveis (Ibama); os Núcleos de Educação Ambiental; as Comissões Interinstitucionais Estaduais de Educação Ambiental; e a Rede Brasileira de Educação Ambiental (REBEA). Houve as elaborações da Carta Brasileira para a Educação Ambiental e do tratado de Educação Ambiental para Sociedades Sustentáveis e Responsabilidade Global, além da criação do Programa Nacional de Educação Ambiental (Pronea) e da aprovação dos Parâmetros Curriculares Nacionais (PCN). Foi incluso no Plano Plurianual (PPA) (1996-1999) do governo federal "a promoção da Educação Ambiental, através da divulgação e uso de conhecimentos sobre tecnologias de gestão 
sustentáveis de recursos naturais". O decênio também foi marcado pela I Conferência Nacional de Educação Ambiental, pela Jornada Internacional de Educação Ambiental e pela aprovação da Lei n 9.795/99, a qual dispõe sobre a Política Nacional de Educação Ambiental (PNEA) (IBAMA, 1998; MACHADO, 2013; MMA, 2018).

Na década de 2000, a EA é novamente integrada ao PPA (2000-2003) por meio do programa 0052, vinculado ao MMA, tendo sido reformulado no PPA (2004-2007), passando a ser intitulado de "Educação Ambiental para Sociedades Sustentáveis". Houve a regulamentação da Lei n 9.795/99 pelo Decreto $\mathrm{n}^{\circ}$ 4.281, bem como a instauração da Comissão Intersetorial de Educação Ambiental (Cisea) e a reestruturação da Coordenação-Geral de EA. Foi instalado o Órgão Gestor da PNEA e o seu Comitê Assessor, além do lançamento do novo ProNEA. A partir da divisão do Ibama, foi constituído o Instituto Chico Mendes de Conservação da Biodiversidade (ICMBio) e a estruturação de sua área de EA. Nesse ínterim, aconteceram eventos como a Conferência Nacional do Meio Ambiente; Encontro Governamental Nacional sobre Políticas Públicas de Educação Ambiental; Fórum Brasileiro de Educação Ambiental; Congresso Ibero-Americano de Educação Ambiental; e Conferência Nacional do Meio Ambiente versão infanto-juvenil (MACHADO, 2013; MMA, 2018).

Entre os anos de 2012 e 2018 diversos acontecimentos permearam o cenário brasileiro, como o lançamento da Rede Planetária de Educação Ambiental e a aprovação das Diretrizes Curriculares Nacionais para a Educação Ambiental. O Ibama aprovou a Instrução Normativa $n^{\circ} 2$, que trata da EA nos processos de licenciamento ambiental federal. Além disso, no PPA (2012-2015) a EA passou a ser inserida no programa Licenciamento e Qualidade Ambiental, bem como em iniciativas transversais de outros programas. O Decreto no $8.235 / 14$ passou a estabelecer normas aos programas de regularização ambiental dos Estados e do Distrito Federal, incluindo a EA como processo apoiador da regularização ambiental de imóveis rurais. Foi instituído o Plano Nacional de Juventude e Meio Ambiente, a criação da Comissão Intersetorial Permanente de Educação Ambiental e da ANPPEA Articulação Nacional de Políticas Públicas de Educação Ambiental, a qual lançou indicadores que serão base para estruturação de uma plataforma nacional de EA. O PPA de 2016-2019 trouxe a EA como elemento para o cumprimento de objetivos voltados à conservação ambiental e à educação formal. Além disso, ocorreram a II Jornada Internacional de Educação Ambiental durante a Rio+20; a IV Conferência Nacional do Meio Ambiente; e os Fóruns Brasileiros de Educação Ambiental (MMA, 2018).

Assim, no tocante à institucionalização da EA como política pública brasileira, tem-se que seus avanços se deram inicialmente por meio da Lei de Diretrizes e Bases da Educação Nacional (LDB) no 9.394/96. Posteriormente, a Educação Ambiental é indicada nos Parâmetros Curriculares Nacionais como tema transversal a ser inserido nos currículos escolares. Contudo, somente a partir da Lei no 9.795/99, que instituiu a Política Nacional de Educação 
Ambiental (PNEA) é que houve o seu estabelecimento como parte do processo educativo. Consoante a referida lei, em seu art. $2^{\circ}$, preconiza que a "Educação Ambiental é um componente essencial e permanente da educação nacional, devendo estar presente, de forma articulada, em todos os níveis e modalidades do processo educativo, em caráter formal e não-formal' (BRASIL, 1999).

A lei supracitada estabelece que a EA deve ser desenvolvida em todos os níveis e modalidades do ensino formal, abrangendo-se, portanto, a educação superior. Em seu art. $8^{\circ}$, Inciso II, trata da capacitação de recursos humanos, incorporando a dimensão ambiental na formação, especialização e atualização dos profissionais de todas as áreas; a preparação de profissionais orientados para as atividades de gestão ambiental; e a formação, especialização e atualização de profissionais na área de meio ambiente, entre outras.

Adicionalmente, o Programa Nacional de Educação Ambiental (ProNEA) orienta a integração da Educação Ambiental no ensino superior, de forma transversal e transdisciplinar, nas diversas áreas e cursos, de modo que seja referenciada não apenas nos currículos, mas também por meio de núcleos e grupos de pesquisa, bem como por projetos de extensão, tornando-a, portanto, indissociável ao ensino, pesquisa e extensão.

Por essas vias, fica evidenciado que a Educação Ambiental no Brasil deve permear todos os níveis educacionais, assumindo destaque na formação superior, uma vez que, por meio dela, formam-se profissionais que irão atuar no mercado de trabalho, devendo possuir consciência ética e competências técnicas para solucionarem problemas inerentes às questões ambientais, visando o desenvolvimento sustentável.

Tal perspectiva contempla todas as áreas e cursos, incluindo-se a formação em Ciências Contábeis, já que os bacharéis em Contabilidade podem propor ações de melhorias para a produção e para o consumo com vista à sustentabilidade, uma vez que se utilizam da segmentação Contabilidade Ambiental que, com base nos eventos e transações econômico-financeiros relacionados à preservação e recuperação ambiental, evidencia a situação patrimonial e o desempenho das entidades, servindo, portanto, para auxiliar na tomada de decisões dos gestores organizacionais.

\section{A Contabilidade Ambiental como escopo para inserção da Educação Ambiental na formação contábil}

Os debates acerca da Educação Ambiental emergiram a necessidade de sua inserção em todas as áreas de formação profissional, vislumbrando-se, entre outros aspectos, a conscientização e o compromisso dos profissionais em relação ao meio ambiente.

Apesar de haver uma indicação da EA para todas as áreas, percebe-se que em algumas profissões ela se faz urgente, tendo em vista a práxis que será desempenhada no labor profissional, como é o caso do contador, uma vez 
que tal profissional prestará informações que auxiliará na tomada de decisões no que tange aos eventos ambientais relacionados às empresas.

Esse requerimento se dá pelo fato de as entidades estarem sendo compelidas ao ajustamento com o desenvolvimento sustentável, devendo considerar, portanto, suas dimensões econômica, social e ambiental, de modo a evidenciar para a sociedade todas as medidas adotadas pela gestão, bem como os resultados obtidos por meio do seu processo de preservação e conservação do meio ambiente.

Neste contexto, tem-se que a contabilidade, enquanto ciência social aplicada com a finalidade de fornecer informações úteis para o processo decisório dos shareholder, bem como dos stakeholders, tem inserido as questões ambientais em seus instrumentos, de modo a auxiliar nos processos de reconhecimento, mensuração e divulgação de informações socioambientais acerca das ações realizadas pelas empresas (SAMPAIO, 2011).

Destaca-se, contudo, que a contabilidade não estava apta a apresentar informações econômicas e financeiras no que concerne à preservação ambiental. Porém, os debates internacionais ecológicos, sociais e ambientais deram surgimento a um novo campo de discussão das Ciências Contábeis: a Contabilidade Ambiental (SILVA, 2012).

Assim, a Contabilidade Ambiental para atender aos seus propósitos passou a direcionar as informações da contabilidade tradicional no sentido de mensurar e evidenciar, em suas contas, os impactos ambientais provocados por meio das atividades realizadas pelas empresas (EUGÉNIO, 2004).

Neste sentido, a Contabilidade Ambiental objetiva identificar, mensurar, esclarecer os eventos, bem como as transações econômico-financeiras relacionadas à proteção, preservação e recuperação ambiental, com vistas a evidenciar a situação patrimonial empresarial em um determinado período (RIBEIRO, 2005), tendo por finalidade auxiliar as organizações quanto ao uso eficiente dos recursos naturais (TINOCO; ROBLES, 2006).

Para tanto, classifica-se como: 1) Contabilidade Ambiental Nacional, a qual se dedica ao acompanhamento das atividades ambientais de uma nação, além do gerenciamento e controle das atividades econômicas relacionadas ao meio ambiente; 2) Contabilidade Ambiental Gerencial, adotada para o gerenciamento das atividades empresariais, de modo que os seus registros satisfaçam aos gestores quanto à obtenção dos seus objetivos e; 3) a Contabilidade Ambiental Financeira, que visa identificar, avaliar e evidenciar os eventos econômico-financeiros voltados à área ambiental, servindo de instrumento de reporte e comunicação entre as entidades bem como para a sociedade (PAIVA, 2006).

Para atender as suas finalidades, a Contabilidade Ambiental dispõe de classificação própria de contas, como é o caso dos Ativos Ambientais, Passivo e Patrimônio Líquido Ambientais, Receitas, Custos e Despesas Ambientais. 
Nos Ativos Ambientais são registrados todos os bens e direitos pertencentes às empresas, os quais tenham capacidade para gerar benefícios econômicos em períodos futuros visando à preservação, proteção e recuperação ambiental (RIBEIRO, 2010).

Já o Passivo Ambiental, compreende todas as obrigações, voluntárias ou involuntárias, as quais requerão no futuro a entrega de ativos, prestação de serviços ou sacrifício de benefícios econômicos, em decorrência de transações ou operações, sejam elas passadas ou presentes, envolvendo a entidade com o meio ambiente e gerando algum dano ambiental (SILVA, 2012).

No que tange ao Patrimônio Líquido Ambiental (PLA), considera-se que esse compreende o capital social destinado ao meio ambiente, o qual fomenta ações de prevenção, recuperação, monitoramento e reciclagem. Além disso, o PLA pode ser constituído por Reservas para Contingências Ambientais, por Doações e, também, por Subvenções (BRAGA, 2010).

As Receitas Ambientais são definidas como recursos contraídos pela entidade, oriundos das vendas de subprodutos ou de materiais reciclados. Já as Despesas Ambientais se referem ao consumo de ativos aplicados no sistema de gerenciamento ambiental do processo produtivo, bem como em atividade ecológica da organização. E, por fim, os Custos Ambientais são os gastos relativos à preservação e recuperação do meio ambiente vinculado à produção da entidade (CARVALHO, 2012).

Frente ao exposto, percebe-se que para atuar no segmento da Contabilidade Ambiental se faz necessário possuir competências técnicas, tendo em vista sua consonância com as Normas Brasileira de Contabilidade e com a legislação ambiental vigente. Para além disso, urge-se obter conhecimentos acerca das questões ambientais e do desenvolvimento sustentável, pois tais saberes auxiliarão na gestão ambiental, a qual incorpora à gestão estratégica da entidade os princípios e os valores voltados ao alcance de um modelo visando o desenvolvimento sustentável (FERREIRA, 2011).

Por essas vias, evidencia-se a necessidade de insertar nos processos educacionais dos cursos de Ciências Contábeis as questões ambientais e de desenvolvimento sustentáveis, não apenas considerando os dispositivos legais, os Parâmetros e Diretrizes Curriculares, bem como o ProNEA, mas, sobretudo, vislumbrando-se a formação de contadores em linha com as exigências socioambientais da contemporaneidade.

Sabe-se que a EA deve ser integrada de forma transversal, inter e transdisciplinar nas diversas áreas e cursos, sem que haja a instituição de uma disciplina própria para tratar das questões ambientais e do desenvolvimento sustentável. Contudo, considerando que a maioria dos componentes curriculares do curso abrange conteúdos programáticos eminentemente técnicos, uma solução para que haja sua efetivação na formação em Ciências Contábeis, seria adicionar aos conteúdos da Contabilidade Ambiental assuntos 
que versem acerca das questões socioambientais, de modo a preparar o formando a auxiliar na gestão ambiental das empresas.

\section{Resultados e Discussão}

Com o intuito de alcançar o objetivo proposto por este estudo, aplicouse junto a trinta e sete graduandos, matriculados no oitavo período do curso Ciências Contábeis, de uma universidade federal do sertão alagoano, um questionário que serviu como instrumento para a coleta de dados primários da pesquisa.

A primeira parte do questionário buscou levantar informações sobre o perfil dos pesquisados. Indagou-se, portanto, acerca do gênero e faixa etária, bem como se os respondentes, na ocasião da pesquisa, já haviam cursado o componente curricular Contabilidade Ambiental. Tal perfil foi evidenciado na Tabela 1.

Tabela 1: Perfil dos discentes pesquisados.

\begin{tabular}{ccc}
\hline \multicolumn{1}{c}{ Gênero } & Frequência & Percentual \\
\hline Feminino & 18 & $48,6 \%$ \\
\hline Masculino & 19 & $51,4 \%$ \\
\hline Total & $\mathbf{3 7}$ & $\mathbf{1 0 0} \%$ \\
\hline Faixa Etária & Frequência & Percentual \\
\hline De 18 a 27 anos. & 28 & $75,7 \%$ \\
\hline De 28 a 37 anos. & 9 & $24,3 \%$ \\
\hline De 38 a 47 anos. & 0 & $0 \%$ \\
\hline Acima de 48 anos. & 0 & $0 \%$ \\
\hline Total & $\mathbf{3 7}$ & $\mathbf{1 0 0} \%$ \\
\hline Se Cursou a Disciplina & Frequência & Percentual \\
Contabilidade Ambiental & 9 & $24,3 \%$ \\
\hline Sim, na graduação. & 28 & $\mathbf{7 5 , 7 \%}$ \\
\hline Não, nunca cursei. & $\mathbf{3 7}$ & $\mathbf{1 0 0} \%$ \\
\hline Total & mediante dados da pesquisa, 2019.
\end{tabular}

Fonte: Elaborado pelos autores, mediante dados da pesquisa, 2019.

Fica demonstrado, por meio da Tabela 1 , que $48,6 \%$ dos respondentes são do gênero feminino e $51,4 \%$ do sexo masculino, evidenciando que não há grande disparidade entre eles. Além disso, do total de 37 participantes da pesquisa, $75,7 \%$ deles estão na faixa etária entre 18 a 27 anos, enquanto outros $24,3 \%$ correspondem à faixa de 28 a 37 anos, demonstrando que a maioria dos graduandos pesquisados possui idade inferior a 30 anos. Adicionalmente, buscou-se saber se os respondentes já tinham cursando no decorrer de sua formação superior o componente curricular Contabilidade Ambiental, a maior parte $(75,7 \%)$ afirmou nunca ter cursado tal disciplina, enquanto $24,3 \%$ responderam já ter cursado na graduação. Tal constatação permite afirmar que os pesquisados, em sua maioria, não possuem 
conhecimentos técnicos acerca de Contabilidade Ambiental, tendo em vista não terem cursado a disciplina durante sua formação, por se tratar de uma disciplina eletiva, fato que dificultará suas atuações profissionais no que tange aos registros dos fatos ambientais, uma vez que não detêm conhecimentos para tanto, a menos que realizem capacitação posterior.

A segunda parte do questionário versou acerca dos conhecimentos quanto às questões ambientais e do desenvolvimento sustentável.

Neste sentido, buscou-se saber em que fase da formação acadêmica os participantes da pesquisa tiveram acesso às temáticas que tratam de questões ambientais. Os resultados obtidos estão apresentados na Tabela 2.

Tabela 2: Acesso às temáticas que tratam de questões ambientais

\begin{tabular}{lcc}
\hline \multicolumn{1}{c}{ Períodos } & Frequência & Percentual \\
\hline Entre o $1^{\circ}$ e $2^{\circ}$ períodos. & 3 & $8,1 \%$ \\
\hline Entre o $3^{\circ}$ e $4^{\circ}$ períodos. & 3 & $8,1 \%$ \\
\hline Entre o $5^{\circ}$ e $6^{\circ}$ períodos. & 8 & $21,6 \%$ \\
\hline Entre o $7^{\circ}$ e $8^{\circ}$ períodos. & 1 & $2,7 \%$ \\
\hline Em nenhum período. & 22 & $59,5 \%$ \\
\hline \multicolumn{1}{c}{ Total } & 37 & $\mathbf{1 0 0 \%}$ \\
\hline
\end{tabular}

Fonte: Elaborado pelos autores, mediante dados da pesquisa, 2019.

Com base nos achados demonstrados na Tabela 2, pode-se constatar que $59,5 \%$ dos respondentes afirmaram que em nenhum período do curso tiveram acesso às temáticas que tratam de questões ambientais, enquanto $21,6 \%$ deles confirmaram o acesso a tais temáticas entre o 5ำ e 6ํㅜ períodos.

Fazendo uma comparação com a questão anterior, concluiu-se que dos 9 (nove) discentes que cursaram o componente curricular Contabilidade Ambiental, apenas 1 (um) deles considerou não ter tido acesso a essas temáticas em nenhum período formativo. Tal constatação conduz ao entendimento de que a disciplina em tela possibilitou acesso às questões ambientais.

De acordo com Programa Nacional de Educação Ambiental, deve-se integrar a EA no ensino superior de forma transversal, inter e transdisciplinar, nas diversas áreas e cursos. Contudo, os dados obtidos na pesquisa revelam que a maioria dos pesquisados não tiveram a oportunidade de acesso aos conteúdos que abordassem questões ambientais.

Indagou-se aos pesquisados como tomaram conhecimento do termo desenvolvimento sustentável e, sendo assim, as respostas foram apresentadas na Tabela 3. 
Tabela 3: Conhecimento do termo desenvolvimento sustentável

\begin{tabular}{|c|c|c|}
\hline Ocasião em que conheceu o termo & Frequência & Percentual \\
\hline Nunca foi apresentado o conceito em nenhuma disciplina. & 11 & $29,8 \%$ \\
\hline $\begin{array}{l}\text { O termo apareceu em uma ou mais disciplinas, mas não foi } \\
\text { discutido o conceito. }\end{array}$ & 4 & $10,8 \%$ \\
\hline Foi discutido o conceito desse termo em uma ou mais disciplinas. & 9 & $24,3 \%$ \\
\hline Através de palestras, artigos ou eventos científicos. & 12 & $32,4 \%$ \\
\hline Outros. Qual? & 1 & $2,7 \%$ \\
\hline Total & 100 & $100 \%$ \\
\hline
\end{tabular}

Fonte: Elaborado pelos autores, mediante dados da pesquisa, 2019.

Por meio da Tabela 3, pode-se constatar que $32,4 \%$ dos respondentes da pesquisa conheceram o termo desenvolvimento sustentável através de palestras, artigos ou eventos científicos. Outros $29,8 \%$ afirmaram que o referido conceito nunca foi apresentado em nenhuma disciplina do curso. Enquanto, para $24,3 \%$, o conceito foi discutido em uma ou mais disciplinas. Infere-se que esses últimos, em sua maior parte $(55,6 \%)$, cursaram o componente curricular de Contabilidade Ambiental, levando-se a indução de que estes alunos foram oportunizados com discussões acerca do termo desenvolvimento sustentável.

Ressalta-se que o componente curricular Contabilidade Ambiental, por ser de caráter eletivo, nem todos os discentes o cursaram, distanciando-se não só dos conhecimentos técnicos deste segmento da contabilidade, mas também de outras discussões, nomeadamente, as de ordens socioambientais.

Destaca-se que as diretrizes indicadas pela PNEA (BRASIL, 1999), bem como as do ProNEA reforçam o papel da universidade como ambiente de produção e articulação de conhecimentos com vistas as demandas sociais. Logo, tratar das temáticas socioambientais constitui uma responsabilidade das universidades.

Em continuidade, perguntou-se aos participantes da pesquisa se o curso promoveu algum evento científico que contemplasse as questões ambientais e do desenvolvimento sustentável e se alguma disciplina contemplou tais questões. É o que foi evidenciado na Tabela 4.

Tabela 4: Eventos científicos e disciplina que contemplou as questões ambientais e do desenvolvimento sustentável

\begin{tabular}{|c|c|c|}
\hline Eventos Científicos & Frequência & Percentual \\
\hline Sim. & 8 & $21,6 \%$ \\
\hline Não. & 29 & $78,4 \%$ \\
\hline Total & 37 & $100 \%$ \\
\hline $\begin{array}{c}\text { Questões Ambientais e de Desenvolvimento Sustentável } \\
\text { Tratadas em Alguma Disciplina do Curso }\end{array}$ & Frequência & Percentual \\
\hline Não. & 25 & $67,6 \%$ \\
\hline Sim. Qual/is? & 12 & $32,4 \%$ \\
\hline Total & 37 & $100 \%$ \\
\hline
\end{tabular}

Fonte: Elaborado pelos autores, mediante dados da pesquisa, 2019. 
Fica evidenciado pela Tabela 4 que $78,4 \%$ dos respondentes asseguraram que 0 curso não promoveu eventos científicos que contemplassem as questões ambientais e do desenvolvimento sustentável. Já para $21,6 \%$ dos participantes da pesquisa, o curso promoveu eventos com essa abordagem. Evidenciou-se, ainda, que $67,6 \%$ dos concluintes consideram que nenhuma disciplina tratou de questões ambientais e de desenvolvimento sustentável. Por outro lado, do total dos pesquisados, 32,4\% afirmam ter tido disciplina com tais abordagens, indicando, portanto, o componente curricular Contabilidade Ambiental.

Essas questões levantam outro ponto de atenção para o curso, já que - Programa Nacional de Educação Ambiental deixa claro que deve haver a inclusão de abordagem e conteúdo metodológico da EA nos currículos de ensino superior. Essa perspectiva pode ser atendida com a inserção de conteúdos programáticos desta natureza, bem como por meio de eventos com abordagem socioambiental.

Perguntou-se aos discentes qual a importância dos conhecimentos acerca das questões ambientais e do desenvolvimento sustentável para a região em que residem e para a profissão contábil. As respostas obtidas constam na Tabela 5.

Tabela 5: Importância dos conhecimentos acerca das questões ambientais e do desenvolvimento sustentável para a região e para a profissão contábil

\begin{tabular}{lccc}
\hline & Escala de Importância & Frequência & Percentual \\
\hline Sem importância. & 0 & $0 \%$ \\
\hline Pouco importante. & 1 & $2,7 \%$ \\
\hline Importante. & 15 & $40,6 \%$ \\
\hline Muito importante. & 12 & $32,4 \%$ \\
\hline Extremanente importante & Total & 9 & $24,3 \%$ \\
\hline & The & $\mathbf{3 7}$ & $\mathbf{1 0 0} \%$ \\
\hline
\end{tabular}

Fonte: Elaborado pelos autores, mediante dados da pesquisa, 2019.

Conforme Tabela 5, a maioria $(97,3 \%)$ dos respondentes consideram os conhecimentos sobre questões ambientais e do desenvolvimento sustentável entre a seguinte escala: importante (40,6\%), muito importante $(32,4 \%)$ e extremamente importante $(24,3 \%)$. Esses dados revelam que os discentes reconhecem a importância destas temáticas, tanto para a região em que residem, como para a profissão contábil, uma vez que conhecedores dessas questões poderão auxiliar na gestão ambiental das organizações de modo a contribuir para o desenvolvimento da região.

Indagou-se, também, aos graduandos pesquisados, se deve haver uma disciplina de Educação Ambiental no curso de Ciências Contábeis e, ainda, como devem ser tratadas as questões ambientais e do desenvolvimento sustentável no curso. Os dados obtidos foram expressos na Tabela 6, os quais demonstram que $83,8 \%$ dos discentes pesquisados consideram que deve 
haver uma disciplina de Educação Ambiental na formação em Ciências Contábeis e que, na ausência de oferta desta disciplina, as temáticas devem ser tratadas no componente curricular de Contabilidade Ambiental (73\%) ou por meio de palestras, seminários, simpósios e outros eventos científicos $(10,8 \%)$. É o que pode ser constatado na Tabela 6:

Tabela 6: Existência de disciplina de Educação Ambiental na formação em Ciências Contábeis ou como devem ser tratadas as questões ambientais e do desenvolvimento sustentável no curso

\begin{tabular}{lccc}
\hline & Existência de disciplina de EA & Frequência & Percentual \\
\hline \multicolumn{1}{c}{ Tim. } & 31 & $83,8 \%$ \\
\hline Não. & 6 & $16,2 \%$ \\
\hline \multicolumn{1}{c}{$\begin{array}{c}\text { Comal } \\
\text { desenvolvimento sustentável no curso. }\end{array}$} & $\mathbf{3 7}$ & $\mathbf{1 0 0 \%}$ \\
\hline $\begin{array}{l}\text { Na disciplina de Contabilidade Ambiental. } \\
\text { De forma transversal em todas as disciplinas do curso. }\end{array}$ & Frequência & Percentual \\
\hline $\begin{array}{l}\text { Por meio de leituras de artigos em disciplinas específicas do } \\
\text { curso. }\end{array}$ & 3 & $73 \%$ \\
\hline $\begin{array}{l}\text { Por meio de palestras, seminários, simpósios e outros eventos } \\
\text { científicos. }\end{array}$ & 3 & $\mathbf{8 , 1 \%}$ \\
\hline \multicolumn{2}{c}{ Total } & $\mathbf{3 7}$ & $10,8 \%$ \\
\hline
\end{tabular}

Fonte: Elaborado pelos autores, mediante dados da pesquisa, 2019.

Ressalta-se que não há indicação por parte do PNEA e do ProNEA que haja uma disciplina específica de Educação Ambiental nos níveis e modalidades de ensino. Contudo, considerando sua abordagem de forma integrada, transversal, interdisciplinar e em consonância com as orientações e normativos do Conselho Nacional de Educação, bem como dos documentos e agendas globais e locais, como preceitua o Programa Nacional de Educação Ambiental, nada obsta que, além do disposto, seja inserida uma disciplina direcionada a tratar das questões socioambientais. Ademais, existe por parte do ProNEA a orientação de criação e fortalecimento de núcleos e grupos de pesquisa e extensão articulados, de modo a fortalecer os estudos e o campo da Educação Ambiental em todos os níveis e modalidades de ensino, possibilitando a disseminação da EA por meio de palestras e eventos científicos que envolvam a sociedade.

Em linhas gerais, a legislação observa que a EA deve ser referenciada nos Projetos Pedagógicos de Cursos, não necessariamente com uma disciplina, mas conferindo ambientes de debates e atividades práticas, de modo a ultrapassar a instância teórica com a aplicabilidade do conhecimento no campo real, verificando e aperfeiçoando suas ações, bem como analisando os resultados decorrentes (SILVA; HAETINGER, 2012).

Por fim, perguntou-se se os conteúdos que versem acerca da Educação Ambiental podem ser contemplados na disciplina de Contabilidade Ambiental, conforme Tabela 7. 
Tabela 7: Conteúdos que versam sobre Educação Ambiental no componente curricular de Contabilidade Ambiental

\begin{tabular}{lccc}
\hline \multicolumn{2}{c}{ Conteúdos de EA em Contabilidade Ambiental } & Frequência & Percentual \\
\hline $\begin{array}{l}\text { Sim, pois os profissionais de contabilidade necessitam desses } \\
\text { conhecimentos para auxiliar na gestão ambiental das }\end{array}$ & 35 & $94,6 \%$ \\
empresas. & & \\
\hline $\begin{array}{l}\text { Não, pois a disciplina de Contabilidade Ambiental deve } \\
\text { contemplar apenas conteúdos contábeis técnicos. }\end{array}$ & 2 & $5,4 \%$ \\
\hline Total & $\mathbf{3 7}$ & $\mathbf{1 0 0 \%}$ \\
\hline
\end{tabular}

Fonte: Elaborado pelos autores, mediante dados da pesquisa, 2019.

Para a maioria dos respondentes (94,6\%), em conformidade com a Tabela 7, considera que os conteúdos que versam sobre EA podem ser contemplados no componente curricular de Contabilidade Ambiental, pois os profissionais de contabilidade necessitam desses conhecimentos para auxiliar na gestão ambiental das empresas. Apenas $5,4 \%$ dos pesquisados consideram que a disciplina não deve contemplar tais conhecimentos, devendo abranger apenas conteúdos contábeis técnicos. Depreende-se, com isso, que os discentes consideram que os conteúdos relativos à EA podem ser abrangidos na disciplina de Contabilidade Ambiental.

\section{Considerações Finais}

$\mathrm{Na}$ esteira de discussão da diplomacia ambiental, várias reflexões têm sido suscitadas no sentido de harmonizar o crescimento econômico com a preservação e conservação do meio ambiente.

Por essas vias, tem-se que a Educação Ambiental possibilitará que a sociedade compreenda a realidade em que vive e na condição de partícipe busque soluções para os problemas socioambientais que se apresentem, ensejando o desenvolvimento sustentável.

Tendo em vista a importância desta temática, a pesquisa objetivou verificar se o curso de Ciências Contábeis de uma universidade federal do sertão alagoano propicia a Educação Ambiental com vistas ao desenvolvimento sustentável.

Os dados obtidos revelaram que $75,7 \%$ dos graduandos pesquisados não cursaram o componente curricular Contabilidade Ambiental. Como também, 59,5\% dos participantes da pesquisa não tiveram acesso às temáticas de questões ambientais em nenhum período do curso.

Por outro lado, $32,4 \%$ dos discentes tiveram conhecimento do termo desenvolvimento sustentável por meio de palestras, artigos ou eventos científicos. Contudo, $78,4 \%$ dos respondentes afirmaram que o curso não promoveu eventos científicos que contemplassem essas temáticas. Além disso, $67,6 \%$ afirmaram que nenhuma disciplina tratou de questões ambientais e de desenvolvimento sustentável, mesmo a maioria $(97,3 \%)$ considerando a 
importância de tais conhecimentos para a região em que residem e para a profissão contábil.

Destaca-se ainda que $83,8 \%$ dos discentes pesquisados consideram que deve haver um componente curricular de Educação Ambiental na formação contábil e que, na ausência de oferta desta disciplina, as temáticas relativas às questões ambientais e do desenvolvimento sustentável devem ser tratadas no componente curricular de Contabilidade Ambiental (73\%). Consequentemente, para a maioria deles $(94,6 \%)$ os conteúdos que versam sobre EA podem ser contemplados na disciplina Contabilidade Ambiental, pois os profissionais de contabilidade necessitam desses conhecimentos para auxiliar na gestão ambiental das empresas.

Conclusivamente, a pesquisa aponta que o curso de Ciências Contábeis pesquisado não propicia a Educação Ambiental de forma transversal e que, em sua maior parte, os discentes que tiveram acesso às temáticas acerca das questões ambientais e do desenvolvimento sustentável foram aqueles que cursaram o componente curricular Contabilidade Ambiental, intuindo-se que tal disciplina contempla a temática socioambiental.

\section{Referências}

BEUREN, I. M. Como Elaborar Trabalhos Monográficos em Contabilidade. Ed. $3^{\circ}$. São Paulo: Atlas 2012.

BRAGA, C. (org.). Contabilidade Ambiental: Ferramenta para a Gestão da Sustentabilidade. 1. ed. 3. reimpr. São Paulo: Atlas, 2010.

BRASIL. Lei $n^{\circ}$ 6.938, de 31 de agosto de 1981. Dispõe sobre a Política Nacional do Meio Ambiente, seus fins e mecanismos de formulação e aplicação, e dá outras providências. Diário Oficial [da] República Federativa do Brasil, Brasília, DF, 31 ago. 1981. Disponível em: <http://www.planalto.gov.br/ccivil 03/leis/l6803.htm>. Acesso em: 07 jul. 2019.

BRASIL. Lei $n^{\circ}$ 9.795, de 27 de abril de 1999. Dispõe sobre a Educação Ambiental, institui a Política Nacional de Educação Ambiental e dá outras providências. Diário Oficial [da] República Federativa do Brasil, Brasília, DF, 27 abr. $1999 . \quad$ Disponível em: <http://www.planalto.gov.br/ccivil 03/leis/l9795.htm>. Acesso em: 07 jul. 2018.

BRASIL. Ministério do Meio Ambiente. Educação Ambiental por um Brasil sustentável: ProNEA, marcos legais e normativos. Ministério do Meio Ambiente - MMA, Ministério da Educação - MEC. Brasília, DF: MMA, 2018.

CARVALHO, G. M. B. Contabilidade Ambiental: teoria e prática. Curitiba: Juruá, 2012.

CONFERÊNCIA DAS NAÇÕES UNIDAS SOBRE O MEIO AMBIENTE, 1972. Estocolmo. Anais... Estocolmo:[s.n.], 1972. 
EUGÉNIO, T. P. Contabilidade e gestão ambiental. Lisboa: Áreas Editora, 2004.

ESCRIVÃO, G.; NAGANO, M. Gestão do conhecimento na Educação Ambiental: estudo de casos em programas de Educação Ambiental em universidades brasileiras. Perspectivas em Ciência da Informação, Belo Horizonte, v. 19, n. 4: 136-159, Out./Dez., 2014.

FERREIRA, A. C. S. Contabilidade Ambiental: Uma informação para o Desenvolvimento Sustentável. Ed. 3. São Paulo: Atlas, 2011.

GIL, A. C. Como Elaborar Projetos de Pesquisas. Ed. $4^{\circ}$. São Paulo: Atlas, 2002.

GRESSLER, L. A. Introdução à pesquisa: projetos e relatórios. São Paulo: Loyola, 2004.

LEFF, E. Epistemologia Ambiental. São Paulo: Cortez, 2001.

MACHADO. A. G. B. História da Educação Ambiental no Brasil e no mundo. 2013. Disponível em: <https://portalresiduossolidos.com/historia-daeducacao-ambiental-brasil-e-mundo/>. Acesso em: 07 ago. 2019.

MACIEL. C. V. et al. Contabilidade ambiental: um estudo exploratório sobre o conhecimento dos profissionais de contabilidade. Revista Contemporânea de Contabilidade, Santa Catarina, v. 6, n. 11: 137-158, Jan./Jun., 2009.

MARCONI, M. A., LAKATOS, E. M. Metodologia Científica, Ed. $6^{\circ}$. São Paulo: Atlas, 2007.

MORALES, A. G. M. O Processo de formação em Educação Ambiental no ensino superior: trajetória dos cursos de especialização. Revista Eletrônica do Mestrado em Educação Ambiental, Rio Grande, v. 18, Jan./Jun., 2007.

PAIVA, P. R. Contabilidade Ambiental: Evidenciação dos Gastos Ambientais com Transparência Focada na Prevenção. Ed. $1^{\circ}$ e $2^{\circ}$ - São Paulo: Atlas, 2006.

PEREIRA. V. G. Contabilidade Ambiental: um estudo exploratório sobre os conhecimentos dos futuros contadores de uma instituição pública de ensino superior do estado da Paraíba. 2014. Trabalho de Conclusão de Curso (Bacharel em Ciências Contábeis) - Universidade Estadual da Paraíba, Monteiro, 2014.

PORTAL DA EDUCAÇÃO. Conferência de Tbilisi (1977), 2013. Disponível em: <https://www.portaleducacao.com.br/conteudo/artigos/biologia/conferenciade-tbilisi-1977/27425>. Acesso em: 14 mar. 2019.

RIBEIRO, M. S. Contabilidade Ambiental. São Paulo: Saraiva, 2005.

RIBEIRO, M. S. Contabilidade ambiental. São Paulo: Saraiva, 2010.

RIBEIRO. J. A. Contabilidade ambiental: um estudo sobre o conhecimento dos estudantes e profissionais de contabilidade da cidade de Santana do Ipanema-AL. 2018. Trabalho de Conclusão de Curso (Bacharel em Ciências Contábeis) - Universidade Federal de Alagoas, Santana do Ipanema, 2018. 
SAMPAIO, M. S. Percepção dos discentes do curso de ciências contábeis diante das questões socioambientais: um estudo nas IES de Salvador - Bahia. 2011. 138 p. Dissertação de Mestrado (Programa de Pós- Graduação (Sctricto Sensu) em Contabilidade da Faculdade de Ciências Contábeis) - Universidade Federal da Bahia, Salvador, $2011 . \quad$ Disponível em:<http://www.contabeis.ufba.br/Site/arquivos/Editor/file/Mestrado/Disserta\%C 3\%A7\%C3\%B5es/2011/Disserta\%C3\%A7\%C3\%A30\%20M\%C3\%A1rcio\%20S ampaio.pdf>. Acesso em: 24 jul. 2019.

SILVA, B. G. Contabilidade ambiental: Sob a ótica da Contabilidade Financeira. 1. ed. 2. reimpr. Curitiba: Juruá, 2012.

TINOCO, J.E.P. ROBLES, L.T. A contabilidade da gestão ambiental e sua dimensão para a transparência empresarial: Estudo de caso de quatro empresas brasileiras com atuação global. Revista de Administração Pública, Rio de Janeiro, v.40, n.6: 1077-1096, Nov./Dez. 2006. 